\title{
Revascularization of the left anterior descending artery area using a single left internal thoracic artery: Auto-Y composite grafting or sequential bypassing
}

\author{
Won-Chul Cho, MD, Joon Bum Kim, MD, Sung Ho Jung, MD, Seung Hyun Lee, MD, \\ Cheol Hyun Chung, MD, Suk Jung Choo, MD, and Jae Won Lee, MD
}

\begin{abstract}
Objective: To maximize the use of left internal thoracic artery in coronary artery bypass grafting, we have adopted a strategy to revascularize the left anterior descending artery area using a single skeletonized left internal thoracic artery; auto-Y composite grafting and sequential bypassing. This study evaluated graft patency and clinical outcomes after these procedures.
\end{abstract}

\begin{abstract}
Methods: Between 2003 and 2009, 144 patients (112 men; age, $62.9 \pm 8.9$ years) underwent coronary artery bypass grafting using a single left internal thoracic artery graft to bypass the left anterior descending artery and a diagonal branch. Of them, 57 patients underwent sequential anastomosis (sequential group), and 87 underwent auto-Y composite anastomosis (auto-Y group). Graft patency was assessed using serial multidetector computed tomography.
\end{abstract}

\begin{abstract}
Results: There were no early mortalities. During a mean follow-up duration of $66.2 \pm 44.5$ months, there were 8 deaths, including 2 cardiac deaths, and no cases of reintervention. The 2 groups were at similar risks of death on crude and adjusted analyses $(P=.109$ and .216$)$. The 2 -year patency rates for the LAD site were $98 \%$ in the sequential group and $100 \%$ in the auto-Y group $(P=.195)$. The 2 -year patency rates for the diagonal artery site were $100 \%$ in the sequential group and $92.9 \%$ in the auto-Y group $(P=.038)$.

Conclusions: Revascularization of the left anterior descending artery area using a single skeletonized left internal thoracic artery resulted in excellent clinical outcomes and graft patency using either auto-Y or sequential grafting. However, there was a higher rate of diagonal branch graft occlusion after auto-Y compared with sequential grafting. (J Thorac Cardiovasc Surg 2011;142:1464-8)
\end{abstract}

The left internal thoracic artery (LITA) as used for grafting has been demonstrated to have a superior graft patency and has provided excellent clinical results compared with other arterial and venous conduits. ${ }^{1,2}$ Thus, it has been most widely used for left anterior descending artery (LAD) bypassing, which is regarded as of the utmost importance in coronary artery bypass grafting (CABG).

To maximize the benefit of LITA, several groups reported a technique that uses LITA not only for bypassing the LAD but also for bypassing both the LAD and one of the major epicardial coronary arteries at one time. ${ }^{3-6}$ This approach may enhance both graft patency and "complete revascularization" inasmuch as the number of remaining coronary segments requiring revascularization is reduced, and hence those segments can be more easily bypassed

From the Departments of Cardiovascular Surgery, Asan Medical Center, College of Medicine, University of Ulsan, Seoul, Korea.

Disclosures: Authors have nothing to disclose with regard to commercial support.

Received for publication Oct 2, 2010; revisions received Jan 23, 2011; accepted for publication March 1, 2011; available ahead of print April 4, 2011.

Address for reprints: Jae Won Lee, MD, Department of Cardiovascular Surgery, Asan Medical Center, College of Medicine, University of Ulsan, 388-1 Poongnap2dong, Songpa-gu, Seoul 138-736, South Korea (E-mail: jwlee@amc.seoul.kr). 0022-5223/\$36.00

Crown Copyright (C) 2011 Published by Elsevier Inc. on behalf of The American Association for Thoracic Surgery

doi:10.1016/j.jtcvs.2011.03.003 with other conduits. However, the use of a single LITA graft for multiple bypasses has raised concerns regarding graft patency inasmuch as it involves using the distal LITA segment, which has a smaller luminal diameter and greater mural muscularity than the proximal segment.

In our institution, the strategy to revascularize the LAD and a diagonal artery using a single skeletonized LITA has been adopted for the economical use of graft conduits: auto-Y composite grafting and sequential bypassing. This study aimed to evaluate the graft patency and clinical outcomes of these 2 techniques.

\section{METHODS}

\section{Patients}

Of the 2791 patients who underwent CABG in our institution between January 2003 and December 2009, 932 patients underwent both LAD and diagonal artery bypassing. LAD revascularization was done with an in situ LITA in all these patients except for 41, who underwent in situ CABG with the right internal thoracic artery (RITA) to the LAD. Among the 932 patients, the diagonal branch was revascularized using a radial artery in 545, a saphenous vein in 162, a LITA in 41 (patients with RITA-LAD bypassing), a RITA in 20, and other grafts (eg, RITA-radial artery composite conduit, right gastroepiploic artery) in 20 . The other 144 patients underwent distal anastomosis on the LAD and diagonal arteries using a single LITA, and these latter patients were the subject of the present study. Grafting involved either sequential anastomosis $(n=57$; sequential group) or auto- $\mathrm{Y}$ anastomosis $(\mathrm{n}=87$; auto- $\mathrm{Y}$ group). The study protocol was 

Abbreviations and Acronyms
$\mathrm{CABG}=$ coronary artery bypass grafting
$\mathrm{CT}=$ computed tomography
LAD $=$ left anterior descending coronary artery
LITA $=$ left internal thoracic artery
MACCE $=$ major adverse cardiac and cardiovascular events
RITA $=$ right internal thoracic artery

approved by the institutional review board of the Asan Medical Center, Seoul, Korea. The board waived the requirement for informed patient consent in consideration of the retrospective nature of the study.

\section{Surgical Techniques and Postoperative Medications}

The LITA was harvested by a skeletonized method, and was preserved in a sponge with papaverine to avoid spasm. The choice between the auto-Y and the sequential technique was based on the anatomic position of the native LAD diagonal branches (Figure 1) ${ }^{4,7}$ All coronary anastomoses were performed with a double-armed 8-0 polypropylene suture and a continuous suturing technique. The auto-Y graft anastomosis between the small segment of the distal portion of LITA and the LITA was performed with continuous 8-0 polypropylene sutures to form a Y-graft. Sequential anastomosis to a diagonal branch was performed in an endto-side fashion. Statin medication, aspirin, and clopidogrel were routinely prescribed to all of the patients starting from postoperative day 1 or 2 . Statin medication and aspirin were continued indefinitely, whereas clopidogrel was discontinued after 1 year.

\section{Follow-up Coronary Computed Tomographic Angiography}

Coronary computed tomographic (CT) angiograms were performed with a 16-channel multidetector CT (Somatom Sensation 16; Siemens Medical Solutions, Forchheim, Germany) before November 2006 and thereafter with a 64-channel multidetector CT (Somatom Definition; Siemens Medical Solutions). Patients were routinely scheduled for early follow-up coronary CT angiography 1 week postoperatively before discharge. In the presence of nonoliguric renal dysfunction or failure defined as a creatinine level more than $1.4 \mathrm{~g} / \mathrm{dL}$, coronary $\mathrm{CT}$ angiograms were performed after preprocedural $\mathrm{N}$-acetylcysteine medication and appropriate hydration in consenting patients only. In patients with normal renal function, routine follow-up coronary $\mathrm{CT}$ angiograms were performed postoperatively at 6 months, 1 year, and every 2 years thereafter. The graft patency status was classified into 1 of 3 descriptive imaging categories: patent, faint (visualization but with significant stenosis, $>50 \%$ of luminal narrowing, or string sign), or nonvisualized. A nonvisualized graft was regarded as occluded. Sequential segments of grafts were considered as separate grafts. All coronary CT angiograms were reviewed by a single experienced radiologist. During the coronary $\mathrm{CT}$ reviews, brief operation records were referenced to see which grafts were anastomosed to which epicardial arteries, but preoperative coronary angiography data and clinical status were not referenced.

\section{Statistics}

Categorical variables are presented as frequencies and percentages and were compared using $\chi^{2}$ or Fisher's exact tests. Continuous variables are expressed as mean \pm SD or medians with ranges and were compared using the Student unpaired $t$ tests or Mann-Whitney $U$ tests, as appropriate.
Kaplan-Meier curves were used to delineate survival and freedom from graft occlusion (patency rate), and log-rank tests were used to compare the differences in the rates between the 2 groups.

To reduce the effect of treatment selection bias and potential confounding, we performed an adjustment for the differences in the baseline characteristics using a propensity score analysis. The propensity scores were estimated using multiple logistic regression analysis without regard to outcome variables. Prespecified covariates (Table 1) were included in the full nonparsimonious models for the sequential versus auto- $Y$ group. The model was well calibrated (Hosmer-Lemeshow test: $P=.22$ ) with reasonable discrimination $(\mathrm{C}$ statistic $=0.73)$. The propensity score was used as a covariate in statistical models. Cox regression analyses were then repeated, with the inclusion of the propensity score as a potential predictor of clinical outcomes. Results were expressed as hazard ratios with $95 \%$ confidence intervals. SPSS version 14.0 (Korean version; SPSS, Inc, Chicago, Ill) was used for statistical analysis.

\section{RESULTS \\ Baseline Characteristics}

The mean age at surgery was $62.9 \pm 8.9$ years, and 32 $(22.2 \%)$ patients were female. Most patients $(\mathrm{n}=125$, $86 \%$ ) underwent off-pump CABG. More distal anastomoses were made in the auto- $Y$ group than in the sequential group $(4.21 \pm 0.88$ vs $3.65 \pm 0.89 ; P<.0001)$. Preoperative patient characteristics are listed in Table 1.

\section{Clinical Outcomes}

There was no early death. There was 1 case of early stroke, 12 cases of perioperative myocardial infarction ( 3 in the sequential group and 9 in the auto-Y group), and 5 cases of low cardiac output syndrome ( 3 in the sequential group and 2 in the auto-Y group). During a mean follow-up duration of $66.2 \pm 44.5$ months, there were 8 deaths, including 2 cardiac deaths. No patient required reintervention owing to target coronary territory occlusion. The auto-Y and sequential groups were at similar risk of all-cause death and major adverse cardiac and cardiovascular events (MACCE; death, nonfatal myocardial infarction, stroke, and reintervention) on crude $(P=.195$ for death and .953 for MACCE) and adjusted $(P=.216$ for death and .967 for MACCE) analyses (Table 2).

\section{Graft Patency}

Early (within 30 days) postoperative coronary CT angiograms (mean, $6 \pm 3$ days) were performed in 122 patients (43 in the sequential group and 79 in the auto-Y group). The overall early patency rates were $98.6 \%$ and $100 \%$ on the LAD and diagonal sites, respectively (Table 3). During a mean follow-up duration of 12.5 months (range 0.1-81.8 months), a follow-up serial coronary $\mathrm{CT}$ angiogram was done in 134 patients $(93.1 \%$; 50 in the sequential group and 84 in the auto-Y group). Twenty patients were evaluated with 16-channel CT (14 in the sequential group and 6 in the auto-Y group), whereas 114 patients were evaluated with 64-channel CT (36 in the sequential group and 78 in the auto-Y group). This follow-up procedure was not possible 

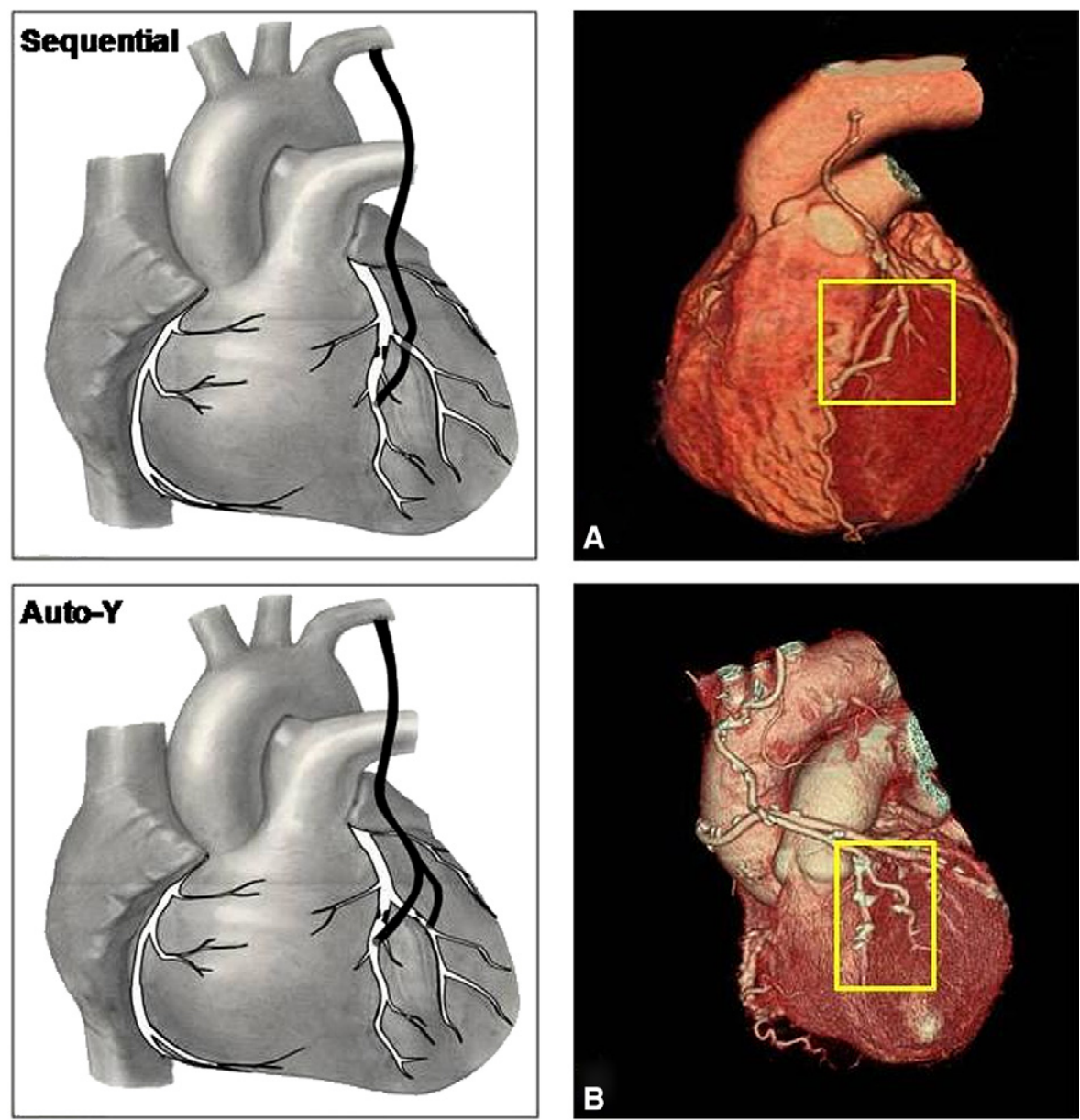

FIGURE 1. Examples of patent grafts after sequential or auto-Y anastomosis. A, Patent sequential grafts at the left anterior descending and diagonal sites. B, Patent auto-Y grafts at the left anterior descending and diagonal artery sites.

in 10 patients owing to renal dysfunction. Of these 10 patients ( 7 in the sequential group, 3 in the auto-Y group), 1 died of intracranial hemorrhage. Nine others had no major adverse cardiac events during follow-up. On serial coronary CT evaluations, the LITA on LAD site was nonvisualized in 1 graft anastomosis only in the sequential group, and the LITA on diagonal site was nonvisualized in 6 graft anastomoses only in the auto-Y group. All nonvisualized grafts on diagonal sites were detected between 6 months to 1 year postoperatively. The overall 2 -year graft patency rate on the LAD sites was $98.0 \% \pm 2.0 \%$ in the sequential group and $100 \%$ in the auto-Y group $(P=.195)$. The 2-year patency rate for diagonal sites was $100 \%$ in the sequential group and $92.0 \% \pm 3.9 \%$ in the auto-Y group $(P=.038)$ (Figure 2). Consequently, the overall 2-year patency rates were $99.3 \%$ for the LAD sites and $95.5 \%$ for diagonal sites.

Crude analysis showed that the auto-Y group was at higher risk of composite MACCE and graft occlusion than was the sequential group $(P=.027)$. However, adjusted analysis showed no significant difference $(P=.107)$.

\section{DISCUSSION}

The present study investigated graft patency and clinical outcomes for 2 bypass techniques (auto-Y and sequential) that used a single LITA for simultaneous LAD and diagonal artery bypassing. The study found that graft patency and clinical outcomes were excellent for both techniques.

Surgical revascularization of the LAD area using the LITA has shown excellent results with superior graft patency and long-term freedom from significant coronary events. ${ }^{3-6}$ To maximize the use of LITA in CABG, our institution has applied the technique of using a single skeletonized LITA to revascularize the LAD and a diagonal artery through auto-Y composite grafting or sequential bypassing. We believe this approach may enhance graft patency and "complete revascularization" outcomes.

The major advantages of the widely applied sequential bypass technique are the saving of bypass conduits and the reduction in the number of proximal anastomoses, which can result in a shorter operation time. ${ }^{8-11}$ In addition, this technique is reported to offer superior hemodynamic and 
TABLE 1. Patient preoperative characteristics

\begin{tabular}{lccc}
\hline & $\begin{array}{c}\text { Sequential } \\
(\mathbf{n}=\mathbf{5 7})\end{array}$ & $\begin{array}{c}\text { Auto-Y } \\
(\mathbf{n = 8 7})\end{array}$ & $\begin{array}{c}\boldsymbol{P} \\
\text { value }\end{array}$ \\
\hline Age, y & $63.2 \pm 8.9$ & $62.7 \pm 8.9$ & .758 \\
Male, n (\%) & $43(75)$ & $69(79)$ & .683 \\
Diabetes mellitus, n (\%) & $33(58)$ & $45(52)$ & .498 \\
Hypertension, n (\%) & $34(60)$ & $57(66)$ & .486 \\
Chronic renal disease, n (\%) & $10(18)$ & $7(8)$ & .113 \\
Current smoking, n (\%) & $25(44)$ & $38(44)$ & .559 \\
Dyslipidemia, n (\%) & $17(30)$ & $15(17)$ & .101 \\
Total no. of distal & $3.65 \pm 0.89$ & $4.21 \pm 0.88$ & .0001 \\
$\quad$ anastomosis, n (\%) & & & \\
Left ventricular ejection & $56.1 \pm 12.6$ & $56.5 \pm 10.7$ & .824 \\
$\quad$ fraction, \% & & & \\
Target stenosis > 90\%, n (\%) & & & \\
$\quad$ Left anterior descending artery & $24(44)^{*}$ & $38(61) \dagger$ & .485 \\
$\quad$ Diagonal artery & $24(44)^{*}$ & $32(42) \dagger$ & .501 \\
Pump strategy, n (\%) & & & .05 \\
$\quad$ Conventional & $3(5)$ & 0 & \\
$\quad$ On-pump beating & $4(7)$ & $12(14)$ & \\
$\quad$ Off-pump & $50(88)$ & $75(86)$ &
\end{tabular}

Numbers of patients whose target vessel stenosis could be measured: $* 55 ; \nmid 76$. Chronic renal disease was defined by nonoliguric renal failure (creatinine level $>2.0 \mathrm{mg} / \mathrm{dL}$ ) or renal failure requiring chronic dialysis.

patency profiles owing to higher mean flows through the grafts, which contributes to superior midterm patency compared with individual bypassing. ${ }^{11,12}$

The LITA length and the geometric relationship between the LAD and diagonal branches should be considered when planning LITA sequential anastomosis. If the angle between the LAD and diagonal branch is acute $\left(<60^{\circ}\right)$, LITA sequential anastomosis is feasible. However, if the lateral distance between the proposed diagonal artery and the LAD is greater than $4 \mathrm{~cm}$, or the angle between the 2 arteries is greater than $60^{\circ}$, sequential anastomosis is generally avoided owing to a tendency for graft kinking just proximal to the sequential anastomosis. ${ }^{4}$ In such cases, using the auto-Y grafting method may reduce the risk of kinking. $4,7,13,14$

The present study found that the 2-year patency rate at the LAD site was $98 \%$ for the sequential method. This rate is comparable with other rates reported for sequential distal

TABLE 2. Crude and adjusted comparative analyses between the auto- $\mathrm{Y}$ and sequential groups in terms of clinical outcomes

\begin{tabular}{|c|c|c|c|c|}
\hline \multirow[b]{2}{*}{ Outcomes } & \multirow{2}{*}{$\begin{array}{c}\text { Crude } \\
P\end{array}$} & \multicolumn{3}{|c|}{$\begin{array}{c}\text { Adjusted by } \\
\text { propensity score }\end{array}$} \\
\hline & & HR & $95 \%$ CI & $P$ \\
\hline Death & .195 & 0.343 & $0.063-1.868$ & .216 \\
\hline MACCE & .953 & 0.980 & $0.374-2.568$ & .967 \\
\hline MACCE + graft occlusion & .027 & 2.992 & $0.789-11.35$ & .107 \\
\hline
\end{tabular}

MACCE, Major adverse cardiac and cardiovascular events including death, nonfatal myocardial infarction, stroke and reintervention; $H R$, hazard ratio; $C I$, confidence intervals.
TABLE 3. Early graft patency rates

\begin{tabular}{lrrc}
\hline \multicolumn{1}{c}{ Variables, $\mathbf{n}(\%)$} & Total & Patent & Nonvisualization \\
\hline Left anterior descending site & 122 & $122(98.6)$ & \\
Sequential & 43 & $42(97.7)$ & $1(2.3)$ \\
Auto-Y & 79 & $79(100)$ & 0 \\
Diagonal site & 122 & $122(100)$ & \\
Sequential & 43 & $43(100)$ & 0 \\
Auto-Y & 79 & $79(100)$ & 0 \\
\hline
\end{tabular}

grafting at the LAD site. ${ }^{3,5,6}$ For the auto-Y technique, we found that the 2-year patency rates were $100 \%$ for the LAD site and $93 \%$ for the diagonal site. These rates are similar to those reported for $\mathrm{Y}$ grafts using the LITA, RITA, or radial artery in other studies. ${ }^{15,16}$

The auto-Y graft usually comprises the distal LITA region. This region has a small lumen and a greater muscular component given the same luminal area, and this may increase the risk of spasticity and affect graft patency. However, several groups reported that these histologic patterns were not associated with the spastic nature or vascular remodeling in distal internal thoracic artery grafts. ${ }^{17,18}$ The present excellent patency rates are consistent with those findings.

In the presence of significant stenosis, any epicardial artery with a luminal diameter greater than 1 to $1.25 \mathrm{~mm}$ was considered for revascularization during $\mathrm{CABG}$ in our institution. Although there are controversies on whether to go on to complete revascularization or to bypass culprit lesions only, the current guidelines recommend complete revascularization. ${ }^{19,20}$ In that aspect, we believe that the

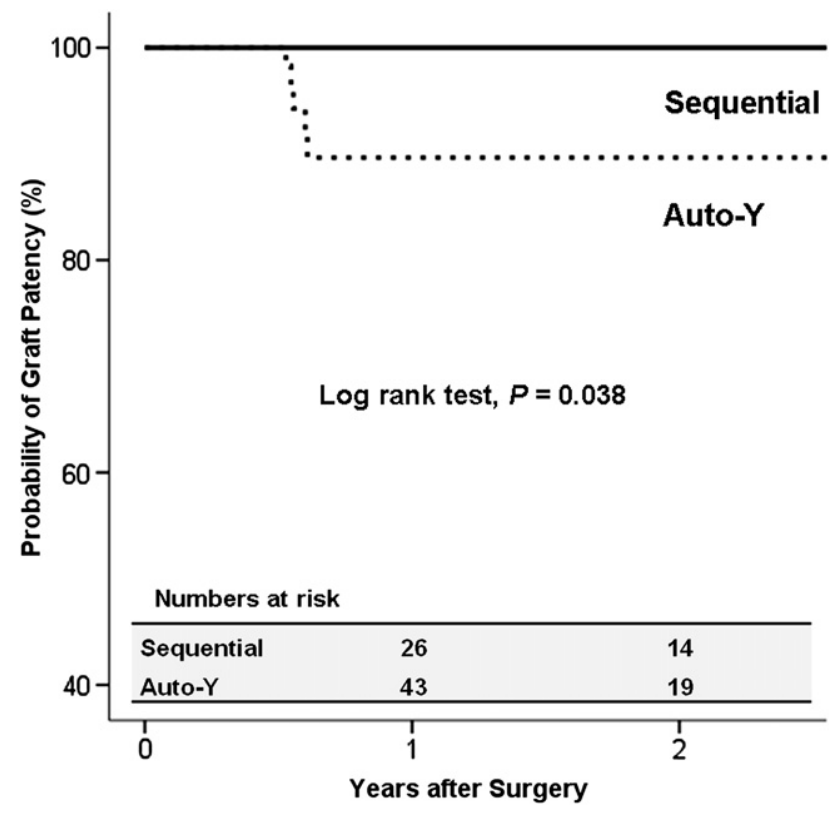

FIGURE 2. Patency rates in the sequential and auto-Y groups for diagonal artery site. 
diagonal branch should also be bypassed whenever possible.

\section{Study Limitations}

The present study was subject to the limitations inherent in retrospective observational data studies. The use of multidetector CT instead of selective coronary angiograms, which are currently regarded as the "gold standard" for patency assessment, may also be considered a study limitation. However, multidetector CT has gained a considerable level of acceptance as a reliable diagnostic cardiac imaging modality. For the detection of significant $(\geq 50 \%)$ graft stenosis, the sensitivity and specificity of 16-channel multidetector CT is reported to be $100 \%$ and $94 \%$, respectively. ${ }^{21}$ The categorization of graft patency in this study was not done in a rigorous manner. Further studies involving predefined patency criteria may verify the results of our study.

With all the statistical methods to adjust the differences in the baseline profiles between the 2 groups, the differences in anatomic relationship between LAD and diagonal branch were not adjustable. Therefore, confounding effects of this anatomic factor cannot be excluded in comparing the outcomes between the 2 groups.

The relatively small number of patients included in this study is another limitation of this study. Inferior patency rate of auto-Y grafting, but comparable reintervention rate, may be attributed to a small sample size. Studies on a larger population are needed to clarify the results of this study.

\section{CONCLUSIONS}

The use of a single skeletonized LITA to revascularize the LAD and a diagonal branch was found to result in excellent clinical outcomes and graft patency. However, auto-Y grafting resulted in a higher rate of graft occlusion in the diagonal branch compared with sequential bypassing.

The auto-Y approach may be useful when the geometric relationship between the LAD and the diagonal branches limits the use of sequential bypassing.

\section{References}

1. Loop FD, Lytle BW, Cosgrove DM, Stewart RW, Goormastic M, Williams GW, et al. Influence of the internal-mammary-artery graft on 10-year survival and other cardiac events. N Engl J Med. 1986;314:1-6.

2. Goldman S, Zadina K, Moritz T, Ovitt T, Sethi G, Copeland JG, et al. Long-term patency of saphenous vein and left internal mammary artery grafts after coronary artery bypass surgery: results from a Department of Veterans Affairs Cooperative Study. J Am Coll Cardiol. 2004;44:2149-56.

3. Bakay C, Erek E, Salihoğlu E, Kinoğlu B, Oztürk S. Sequential use of internal thoracic artery in myocardial revascularization: mid- and long-term results of 430 patients(1). Cardiovasc Surg. 2002;10:481-8.

4. Boustany CW, Mills NL. Sequential coronary artery bypass utilizing the internal mammary artery. J Cardiovasc Surg (Torino). 1988;29:123-7.

5. van Sterkenburg SM, Ernst SM, Brutel de la Rivière A, Defauw JA, Hamerlynck RP, Knaepen PJ, et al. Triple sequential grafts using the internal mammary artery: an angiographic and short-term follow-up study. $J$ Thorac Cardiovasc Surg. 1992;104:60-5.

6. Dion R, Glineur D, Derouck D, Verhelst R, Noirhomme P, El Khoury G, et al. Long-term clinical and angiographic follow-up of sequential internal thoracic artery grafting. Eur J Cardiothorac Surg. 2000;17:407-14

7. Kesler KA, Sharp TG, Turrentine MW, Brown JW. Technical considerations and early results of sequential left internal mammary artery bypass grafting to the left anterior descending coronary artery system. J Card Surg. 1990;5:134-44.

8. Meeter K, Veldkamp R, Tijssen JG, van Herwerden LL, Bos E. Clinical outcome of single versus sequential grafts in coronary bypass operations at ten years' follow-up. J Thorac Cardiovasc Surg. 1991;101:1076-81.

9. Grondin CM, Limet R. Sequential anastomoses in coronary artery grafting: technical aspects and early and late angiographic results. Ann Thorac Surg. 1977;23: $1-8$.

10. Kieser TM, FitzGibbon GM, Keon WJ. Sequential coronary bypass grafts: longterm follow-up. J Thorac Cardiovasc Surg. 1986;91:767-72.

11. O'Neill MJ, Wolf PD, O'Neill TK, Montesano RM, Waldhausen JA. A rationale for the use of sequential coronary artery bypass grafts. J Thorac Cardiovasc Surg. 1981;81:686-90.

12. Kim HJ, Lee TY, Kim JB, Cho WC, Jung SH, Chung CH, et al. The impact of sequential versus single anastomoses on flow characteristics and mid-term patency of saphenous vein grafts in coronary bypass grafting. J Thorac Cardiovasc Surg. 2011;141:750-4.

13. Odayan MK, Paterson HS. Myocardial revascularization with the left internal thoracic artery Y graft configuration. Ann Thorac Surg. 1999;67:1359-61.

14. Yie K, Kim SH, Bang JH, Woo JS, Na CY, Oh SS. Off-pump total left anterior descending area re-vascularisation using left internal thoracic artery auto Y graft: angiographic early and 3-year follow-up results. Eur J Cardiothorac Surg. 2009; 36:1006-10.

15. Bonacchi M, Prifti E, Maiani M, Frati G, Giunti G, Di Eusanio M, et al. Perioperative and clinical-angiographic late outcome of total arterial myocardial revascularization according to different composite original graft techniques. Heart Vessels. 2006;21:69-77.

16. Jung SH, Song H, Choo SJ, Je HG, Chung CH, Kang JW, et al. Comparison of radial artery patency according to proximal anastomosis site: direct aorta to radial artery anastomosis is superior to radial artery composite grafting. $J$ Thorac Cardiovasc Surg. 2009; 138:76-83.

17. Marx R, Clahsen H, Schneider R, Sons H, Klein RM, Gulker H. Histomorphological studies of the distal internal thoracic artery which support its use for coronary artery bypass grafting. Atherosclerosis. 2001;159:43-8.

18. Svendsen E, Dregelid E, Eide GE. Internal elastic membrane in the internal mammary and left anterior descending coronary arteries and its relationship to intimal thickening. Atherosclerosis. 1990;83:239-48.

19. Kolh P, Wijns W, Danchin N, Di Mario C, Falk V, Folliguet T, et al. Guidelines on myocardial revascularization. Eur J Cardiothorac Surg. 2010;38(Suppl): S1-52.

20. Wijns W, Kolh P, Danchin N, Di Mario C, Falk V, Folliguet T, et al. Guidelines on myocardial revascularization: The Task Force on Myocardial Revascularization of the European Society of Cardiology (ESC) and the European Association for Cardio-Thoracic Surgery (EACTS). Eur Heart J. 2010;31:2501-55.

21. Salm LP, Bax JJ, Jukema JW, Schuijf JD, Vliegen HW, Lamb HJ, et al. Comprehensive assessment of patients after coronary artery bypass grafting by 16 -detector-row computed tomography. Am Heart J. 2005;150:775-81. 